\title{
Respiratory syncytial virus and palivizumab: Where are we in 2014?
}

\author{
Joan Robinson MD
}

$P_{\mathrm{b}}$ livizumab is a recombinant humanized murine monoclonal antibody directed against an epitope on the F glycoprotein of respiratory syncytial virus (RSV). The two original randomized controlled trials used five monthly doses as prophylaxis in preterm infants (1) and children with congenital heart disease (2), demonstrating efficacy in preventing RSV hospitalizations ranging from approximately $50 \%$ in preterm infants with chronic lung disease and infants with congenital heart disease (number needed to treat [NNTT] 20 to 23) to $80 \%$ in preterm infants without chronic lung disease (NNTT 12 to 16) (3). It has recently been shown that there can be false-negative results for the detection of RSV in the presence of palivizumab (4); thus, the NNTT may be higher than reported in these studies. A recent randomized controlled trial demonstrated that palivizumab administered to healthy infants born at 33 to 35 weeks' gestation for their first RSV season decreased days with wheezing in the first year of life from $4.5 \%$ to $1.8 \%(\mathrm{P}<0.001)$ and decreased the incidence of recurrent wheezing from $21 \%$ to $11 \%(\mathrm{P}=0.01)$, with the positive effect persisting beyond the RSV season (5). Palivizumab appears to be remarkably safe, with the only serious adverse event being rare cases of anaphylaxis.

Most Canadian children are offered palivizumab monthly throughout their first and sometimes their second RSV season if they were born before 32 weeks' gestational age, have chronic lung disease of prematurity or have hemodynamically significant congenital heart disease. Indications for use at 32 to 36 weeks' gestation vary across the country. Many jurisdictions use some modification of a scoring tool developed in Canada (6) with an estimated NNTT of 11 to 18 to prevent $80 \%$ of hospitalizations (3).

Indications for palivizumab remain controversial because the drug is costly (the drug cost in Canada is approximately $\$ 7,500$ for five doses for a child with a mean weight of $5 \mathrm{~kg}$ ). Wastage is common because vials are preservative free. Although palivizumab is not a blood product, it was initially distributed by Canadian Blood Services. This resulted in it not being evaluated by the same processes that are applied to new vaccines or pharmaceuticals. Decisions about use in each jurisdiction are made by varying combinations of representatives from infectious diseases, neonatology, pulmonary, public health and nursing, with decisions about children who do not meet the standard indications sometimes being made by a single physician.

There remain many unanswered questions about palivizumab:

- Should the complexity of neonatal intensive care unit discharge date be factored in when deciding which infants to prophylax? A study from British Columbia showed that discharge date is more predictive of RSV hospitalization than birth date (7).

- Should twins receive palivizumab if only one meets the eligibility criteria?

- If a child develops breakthrough RSV, should palivizumab be continued? Second RSV infections during one season occur and the product monograph recommends continuation, but the NNTT is no doubt very high.

- Should palivizumab be used in children $>2$ years of age? Almost all children experience RSV infection in the first two years of life and then experience repeated, milder infections throughout life. Severe RSV infections are rare in children $>2$ years of age, but do occur in children with severe chronic diseases. There are no data regarding the rates of RSV hospitalization in children $>2$ years of age with specific underlying conditions. Administration typically requires $>3$ intramuscular injections per dose or off-label intravenous use.

- Should palivizumab be used to potentially prevent outbreaks of nosocomial RSV in neonatal intensive care units, as it is being used in some Canadian centres? Administering doses to infants long before the anticipated discharge date adds to the expense in an attempt to prevent a relatively rare event. It appears likely that improved infection control practices or administration of palivizumab to high-risk infants once a nosocomial case is identified are less expensive strategies.

- Should palivizumab be given to term infants in remote communities? Two studies have documented extraordinarily high rates of RSV hospitalization in specific communities in Nunavut $(8,9)$. Administration of palivizumab is sufficiently complicated in remote communities that even reaching all infants who fit the standard criteria is challenging.

- When in the year should one begin to administer palivizumab? Similar to influenza season, RSV season in Canada typically starts in November, December or January. However, the season often starts later in more northern regions. Some palivizumab programs use the same start date every year because this simplifies booking clinics. Other programs wait until there is significant local RSV activity. A recent study demonstrated that for a four-year period in Hamilton (Ontario), use of a fixed start date would have increased costs because a median of one extra dose per child would have been required to prophylax to the end of RSV season (10). The decision regarding when to give the first dose is especially complicated in the far north. It is suboptimal to match the start date to that of the closest large city, often thousands of kilometers south. On the other hand, a significant number of cases may occur before RSV is documented locally and palivizumab administered, given the turnaround time for laboratory results from remote communities.

- How many doses of palivizumab should be given during RSV season? RSV season lasts longer than influenza season. The median duration in the recent study in Hamilton was 125 days, with a range of 90 to 181 days (10). There are surprisingly few studies investigating serum palivizumab levels (11). The level that is postulated to prevent RSV hospitalization is based solely on the fact that a trough of $25 \mu \mathrm{g} / \mathrm{mL}$ to $30 \mu \mathrm{g} / \mathrm{mL}$ decreased RSV titres by an average of $99 \%$ in the lungs of cotton rats (12) with all achieving a $99 \%$ drop at $40 \mu \mathrm{g} / \mathrm{mL}$ (13). Even if $40 \mu \mathrm{g} / \mathrm{mL}$ is the correct target trough in children, lower doses (14), less frequent dosing or a smaller number of total doses (3) have the potential to protect children throughout RSV season because the trough remains above the target range for $>30$ days following the third dose $(12,15)$. Based on this premise, the British Columbia program administers a maximum of three doses to many children, with no apparent increase in breakthrough hospitalizations (16). A maximum of three doses appears to be especially appropriate if one chooses to prophylax infants born at 32 to 36 weeks' gestation because their risk of RSV hospitalization approximates

Correspondence: Dr Joan Robinson, University of Alberta and Stollery Children's Hospital, 3-556 Edmonton Clinic Health Academy, 11405-87 Avenue, Edmonton, Alberta T6G 1C9. Telephone 780-248-5540, fax 888-790-1176, e-mail jr3@ualberta.ca 
that of a one-month-old term infant when they reach four months of age (17).

- What is the optimal spacing between the first two doses? To attempt to remain above the theoretical target trough of $40 \mu \mathrm{g} / \mathrm{mL}$, some Canadian programs still administer the second dose three weeks after the first dose. However, this is not the recommended practice in the product monograph and there are no data showing that this practice improves outcomes.

- Should palivizumab ever be used for treatment of severe RSV? A 2011 systematic review found no evidence of benefit (18); however, it is not unusual for desperate physicians to administer palivizumab intravenously to children or even immunocompromised adults.

- Is palivizumab cost effective? Disparate results of cost analyses correlate with whether the study was industry sponsored (19). Because the cost of five doses is higher than the cost of most RSV admissions, palivizumab can only be cost effective in fly-in communities with aberrantly high hospitalization rates (8), or if palivizumab prevents mortality or long-term morbidity. There is no evidence that breakthrough infections are more severe than those in children who were not prophylaxed or that palivizumab prevents deaths. Although palivizumab prevents wheezing in the first year of life (4), more data are required to determine whether there is an impact on the incidence or severity of asthma. A

\section{REFERENCES}

1. Palivizumab, a humanized respiratory syncytial virus monoclonal antibody, reduces hospitalization from respiratory syncytial virus infection in high-risk infants. The Impact-RSV Study Group. Pediatrics 1998;102:531-7.

2. Feltes TF, Cabalka AK, Meissner HC, et al. Palivizumab prophylaxis reduces hospitalization due to respiratory syncytial virus in young children with hemodynamically significant heart disease. J Pediatr 2003;143:532-40.

3. Robinson JL; Canadian Paediatric Society, Infectious Diseases and Immunization Committee. Preventing respiratory syncytial virus infections. Paediatr Child Health 2011;16:487-8.

4. Deming DJ, Patel N, McCarthy MP, Mishra L, Shapiro AM, Suzich JA. Potential for palivizumab interference with commercially available antibody-antigen based respiratory syncytial virus diagnostic assays. Pediatr Infect Dis J 2013;32:1144-6.

5. Blanken MO, Rovers MM, Molenaar JM, et al. Respiratory syncytial virus and recurrent wheeze in healthy preterm infants. N Engl J Med 2013;368:1791-9.

6. Sampalis JS, Langley J, Carbonell-Estrany X, et al. Development and validation of a risk-scoring tool to predict respiratory syncytial virus hospitalization in premature infants born at 33 through 35 completed weeks of gestation. Med Decis Making 2008;28:471-80.

7. Solimano A, Lavoie P, Taylor R, Bayzand L. Discharge date is a better predictor of probability of RSV hospital admission than date of birth. Abstract 1516.293. Pediatric Academic Societies Meeting. Boston, April 28 to May 1, 2012.

8. Banerji A, Lanctôt KL, Paes BA, et al. Comparison of the cost of hospitalization for respiratory syncytial virus hospitalization versus palivizumab prophylaxis in Canadian Inuit infants. Pediatr Infect Dis J 2009;28:702-6.

9. Banerji A, Panzov V, Robinson J, Young M, Ng K, Mamdani M. The cost of lower respiratory tract infections hospital admissions in the Canadian Arctic. Int J Circumpolar Health 2013;72.

10. Paes BA, Craig C, Pigott W, Latchman A. Seasonal respiratory syncytial virus prophylaxis based on predetermined dates versus regional surveillance data. Pediatr Infect Dis J 2013;32:e360-e364.

11. Robbie JG, Zhao L, Mondick J, Losonsky G, Roskos LK. Population pharmacokinetics of palivizumab, a humanized provocative commentary recently suggested that given the cost:benefit ratio, indications for palivizumab should be further restricted (19).

- Will palivizumab resistance become a clinically significant phenomenon? A recent Canadian study found that RSV mutants that interfered with palivizumab binding were detected in two of $23(9 \%)$ palivizumab recipients and zero of 100 controls (20).

- Perhaps most importantly, how do we ensure that use of palivizumab is equitable across Canada? There is no question that if we administered palivizumab to every child with a predictable increased risk of being hospitalized with RSV, we would bankrupt the health care system while barely changing the total number of RSV hospitalizations because most occur in healthy children.

An update of the 2003 National Advisory Committee on Immunization (NACI) statement on palivizumab (21) could promote uniform use. However, to ensure that use is rational, more data are required. National surveillance for RSV hospitalizations would be beneficial. Even surveillance limited to children with the current indications for palivizumab, intensive care admission, prolonged stays, Down syndrome, cystic fibrosis, neurological disorders and immunodeficiencies could be used to answer many of the above questions. anti-respiratory syncytial virus antibody, in adults and children. Antimicrob Agents Chemother 2012;6:4927-36.

12. Johnson S, Oliver C, Prince G, et al. Development of a humanized monoclonal antibody (MEDI-493) with potent in vitro and in vivo activity against respiratory syncytial virus. J Infect Dis 1997;7:1215-24.

13. Subramanian KNS, Weisman LE, Rhodes T, et al. Safety, tolerance and pharmacokinetics of a humanized monoclonal antibody to respiratory syncytial virus in premature infants and infants with bronchopulmonary dysplasia. Pediatr Infect Dis J 1998;17:110-5.

14. Zaaijer HL, Vandenbroucke-Grauls CM, Franssen EJ. Optimum dosage regimen of palivizumab? Ther Drug Monit 2002;24:444-5.

15. Solimano A, Kwan E. Revisiting palivizumab (PVZ) dosing recommendations based on published pharmacokinetics data. Abstract 4350.8. Pediatric Academic Societies Meeting. Boston, April 28 to May 1, 2012.

16. Solimano A, Taylo R, Wong K, Markowski J, Kwan E, Bayzand L. RSV prophylaxis with palivizumab for risk-selected babies without chronic lung disease born at 32 to 34 weeks in British Columbia: Three doses are as good as five per season. Abstract 1516.294. Pediatric Academic Societies Meeting. Boston, April 28 to May 1, 2012.

17. Winterstein AG, Knox CA, Kubilis P, Hampp C. Appropriateness of age thresholds for respiratory syncytial virus immunoprophylaxis in moderate-preterm infants: A cohort study. JAMA Pediatrics 2013;167:1118-24.

18. Hu J, Robinson JL. Treatment of respiratory syncytial virus with palivizumab: A systematic review. World J Pediatr 2010;6:296-300.

19. Meissner HC, Kimberlin DW. RSV immunoprophylaxis: Does the benefit justify the cost? Pediatrics 2013;132:915-8.

20. Papenburg J, Carbonneau J, Hamelin ME, et al. Molecular evolution of respiratory syncytial virus fusion gene, Canada, 2006-2010. Emerg Infect Dis 2012;18:120-4.

21. National Advisory Committee on Immunization. Statement on the recommended use of monoclonal anti-RSV antibody (palivizumab). Canada Communicable Disease Report 2003;29. <www. collectionscanada.gc.ca/webarchives/20071116032912/http://www. phac-aspc.gc.ca/publicat/ccdr-rmtc/03vol29/acs-dcc-7-8/acs7.html> (Accessed December 16, 2013). 


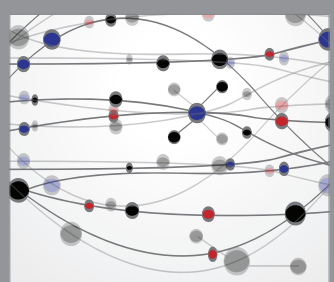

The Scientific World Journal
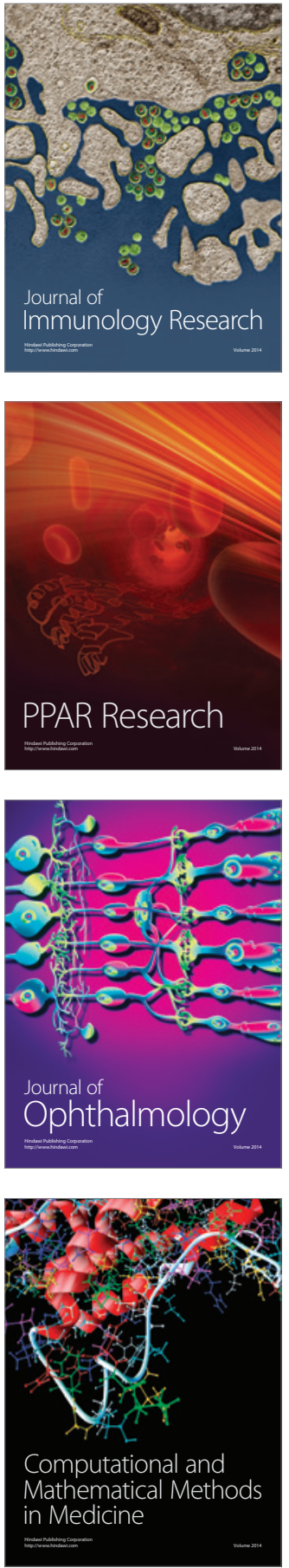

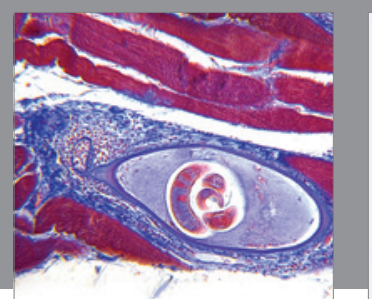

Gastroenterology Research and Practice

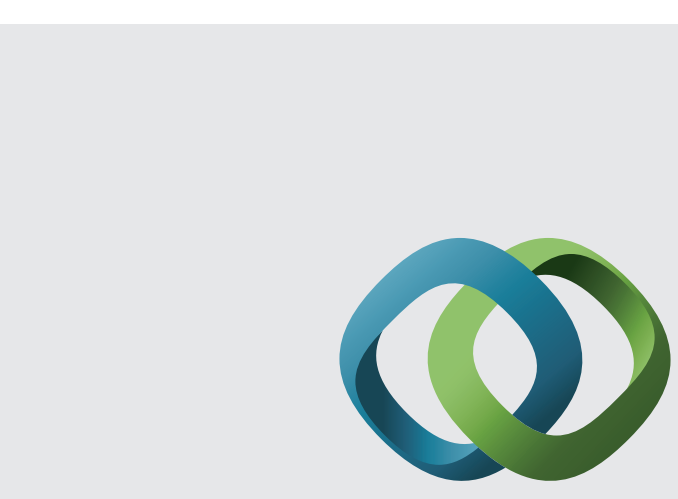

\section{Hindawi}

Submit your manuscripts at

http://www.hindawi.com
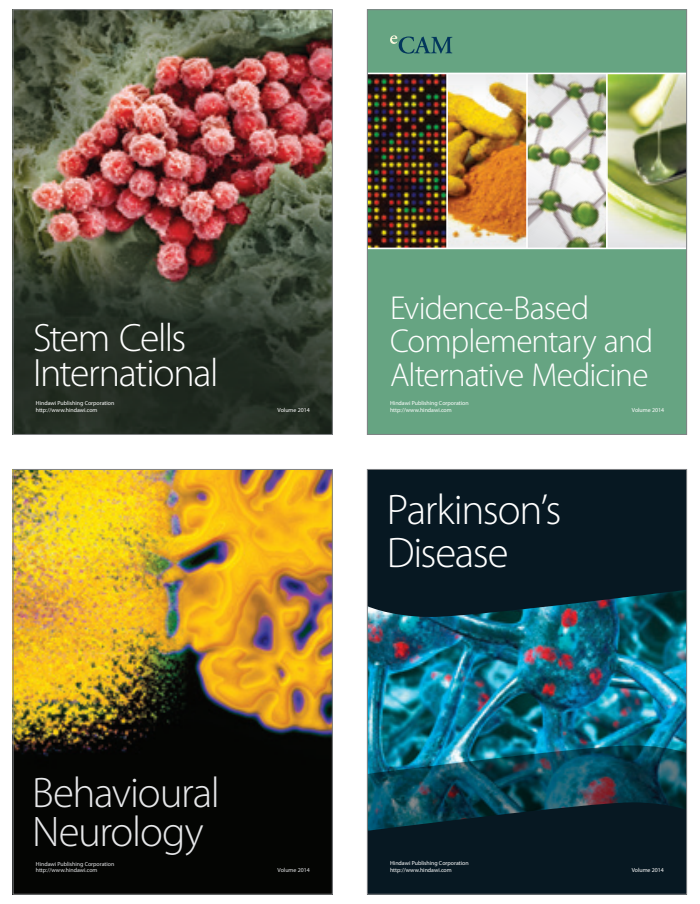
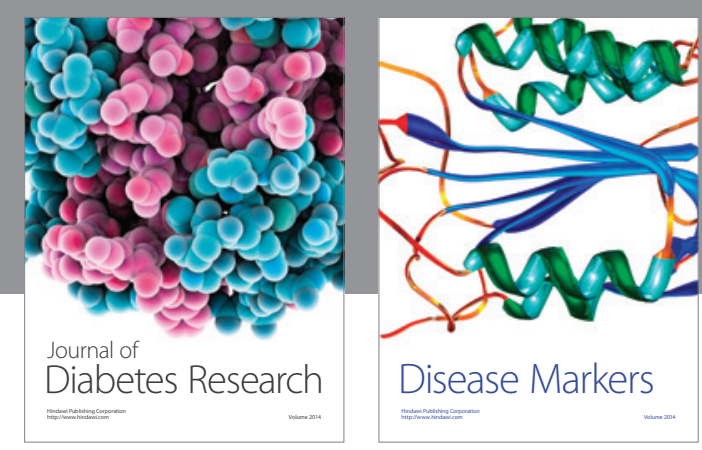

Disease Markers
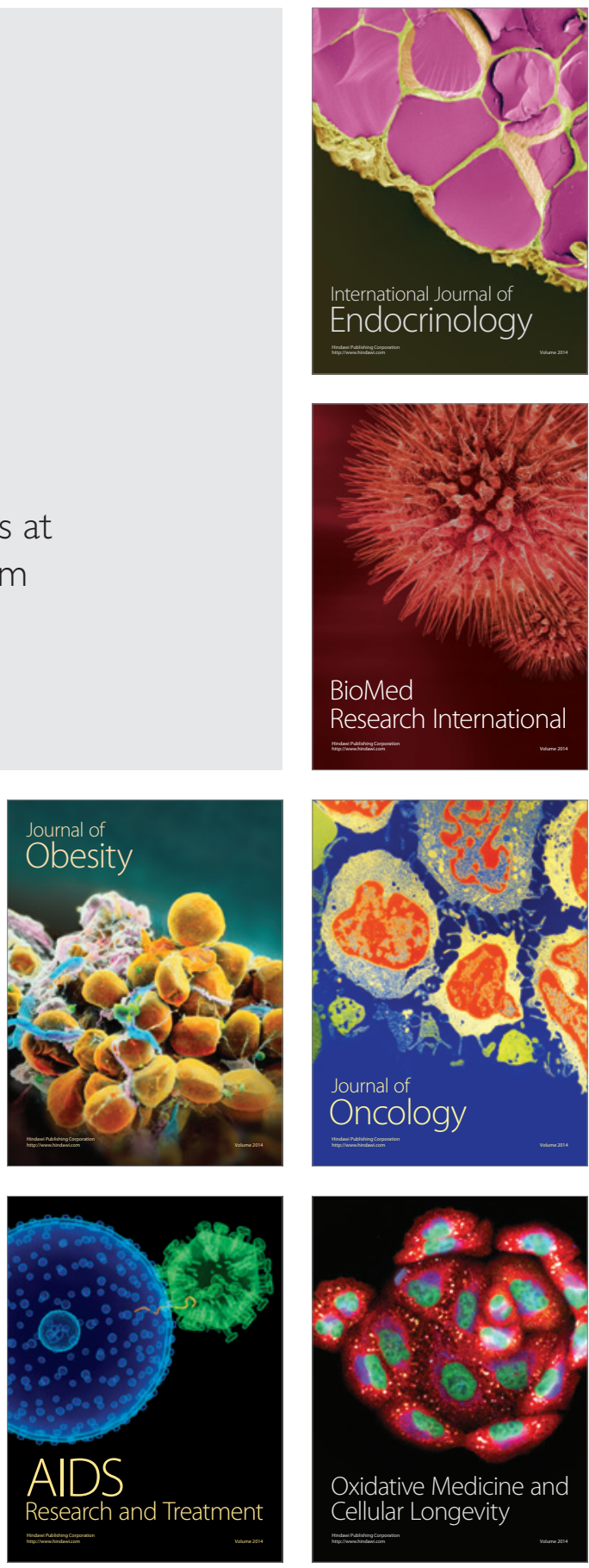